http://jmscr.igmpublication.org/home/ ISSN (e)-2347-176x ISSN (p) 2455-0450 crossref DOI: https://dx.doi.org/10.18535/jmscr/v7i10.15

\title{
Prevalence of High Titre Anti-A and Anti-B Antibodies among Blood Group O Donors at Kenyatta National Hospital Blood Transfusion Unit, Kenya
}

Authors

\author{
Hashim Musa ${ }^{1,3}$, Fatmah Abdallah², Amos Mbugua ${ }^{3}$
}

${ }^{1}$ Department of Laboratory Medicine, Kenyatta National hospital, P.O Box 20723-00202, Nairobi, Kenya

${ }^{2}$ Department Department of Human Pathology, Thematic unit of Hematology and Blood Transfusion,

College of Health Sciences, University of Nairobi, P.O Box 30197-00100, Nairobi, Kenya

${ }^{3}$ Department of Medical Laboratory Sciences, School of Biomedical Sciences, College of Health Sciences, Jomo Kenyatta University of Agriculture and Technology, P.O. Box 62000-00200, Nairobi, Kenya

*Corresponding Author

Hashim Musa Haji

P.O. BOX 229- 00202 Nairobi, Kenya

\begin{abstract}
Introduction: High titres of naturally occurring (IgM) and immune (IgG) blood group antibodies in group $O$ blood are attributed to acute transfusion reactions when this blood is transfused to non $O$ recipients. The objective of this study was to determine the prevalence, and titre levels of $\operatorname{IgM}$ and $\operatorname{Ig} G$ anti-A\& B antibodies among group O donors at Kenyatta National Hospital (KNH) Blood Transfusion Unit.

Method: It was a cross-sectional study involving 233 group $O$ donors. A questionnaire was administered to capture demographics and other variables that are associated with high antibody titre. A $3 \mathrm{ml}$ donor blood was collected from each donor and processed to obtain plasma which was titrated using an immunohematology analyzer (Immucor Neo®).Descriptive statistics was performed on demographics, Chi-square and fisher exact were used to assess association between high titre and these variables.

Results: The age of donor population ranged from 18-58 years with a mean of 29.3(SD \pm 8.7$)$ years. Majority were male 183 (78.5\%). The most common age group was 18-28 years constituting 122(52.4\%)). Using a cut of $\geq 1: 64$, the prevalence of high titre among the group $O$ donors was $75.5 \%$ irrespective of antibody class (IgG and IgM) and specificity (anti-A and anti-B). The percentage with titre $\geq 1: 64$ for IgM anti-A was 36\%, IgM anti-B 26.6\%, IgG anti-A 48.1\% and IgG anti-B 32.2\%. Age, sex, previous history of transfusion, and pregnancy were not associated with high antibody titre. However higher antibody titre was detected among those who did not consume yoghurt $(P=0.03)$.

Conclusion: The study sheds light on the importance of pre-transfusion ABO antibody titration at KNH. Keywords: High titre, anti $A$, anti $B$ antibodies, group $O$ donors, blood transfusion.
\end{abstract}




\section{Introduction}

Since the discovery of ABO blood group by Karl Landsteiner in $1900^{(1)}$, transfusion medicine has continued to evolve with more than 600 red cell antigens and different classes of antibodies indentified so far $^{(2)}$. Of the different blood groups in the ABO system, group $\mathrm{O}$ is the most common in Kenya similar to many other settings globally ${ }^{(3),(4),(5)}$. This blood group has no blood group antigen but has got antibodies against A,B and $\mathrm{AB}$ antigens. These antibodies are either natural or immune. Naturally occurring antibodies (IgM) are produced by the body during neonatal life without any specific antigenic stimuli, whereas immune (IgG) antibodies develop due to immunization either as a result of transfusion of ABO incompatible blood, or following pregnancy of $\mathrm{ABO}$ incompatible fetus, or after vaccination. Some group $\mathrm{O}$ individuals also naturally produce immune IgG antibodies. These immune antibodies have the potential to cross placental barrier and may cause Hemolytic Disease of the New Born (HDN). Transfusion of blood group $\mathrm{O}$ and its components with high $\mathrm{ABO}$ antibody titre to non $\mathrm{O}$ recipients have been shown to cause acute transfusion reactions and other unwanted transfusion related outcomes $^{(6),(7)}$. Furthermore, in this era of advancement in transplantation practice, achieving baseline anti-blood group antibody titre before kidney transplant plus monitoring and maintaining low $\mathrm{ABO}$ antibodies in post-transplant recipients is important in achieving good clinical outcomes among ABO-incompatible donation ${ }^{(8)}$. These antibodies have been suggested to vary in different populations with regard to age, race and gender $^{(9),(10),(11)}$. Some studies have also alluded to the role of environment and diet in influencing the levels of these antibodies ${ }^{(12)}$. There are no published data on the distribution of these antibodies among donors in Kenya. This study therefore looks into the prevalence and factors associated with high titre of anti-A and $\mathrm{B}$ antibodies among blood group $\mathrm{O}$ donors at Kenyatta National Hospital, Kenya.

\section{Materials and Methods}

This was a cross-sectional study. Inclusion criteria required donors to be aged 18 years and above and fit to donate blood according to guidelines from KNBTS (Kenya National Blood Transfusion Services). Ethical approval was sought from Kenyatta National Hospital-University of Nairobi Ethical Review Committee (KNH-UON ERC).

Consent was obtained and a questionnaire was administered to the participant to capture data on factors associated with high antibody titre. A total of 461 blood donors were screened from which 233(50.5\%) were blood group $\mathrm{O}$ who were selected and recruited for the study. From each selected donor, a $3 \mathrm{ml}$ sample was collected from the pilot tube of donors' blood bag into a labelled EDTA tube. The samples were centrifuged to obtain hemoglobin free plasma which was then transferred into labelled cryovials. Titration was conducted using the fully automated Immucor Neo analyzer. Reagents and cells (A1\&B) from Immucor Inc. were used for the procedure. Statistical analysis was performed using SPSS version 21. Mean age, SD, prevalence of high titre were calculated. Association of high titre to age, sex, use of probiotic (yogurt), past history of pregnancy and transfusion were undertaken using Chi-square, and Fisher exact.

\section{Results}

The age of the donor population ranged from 18-58 years with a mean of 29.3(SD \pm 8.7 ) years. Nearly half of the group $\mathrm{O}$ donors recruited into the study were youthful in age 18-28 years. The proportion of female was less than a quarter $(21.5 \%)$, with a male: female ratio of $3.7: 1$. Table 1 illustrates the distribution of age group and gender of the study population.

Table 1: Donor sex and age group frequency

\begin{tabular}{|l|c|}
\hline & Frequency $(\boldsymbol{\%}) \mathbf{N}=\mathbf{2 3 3}$ \\
\hline Sex & $183(78.5)$ \\
Fale & $50(21.5)$ \\
\hline Age group in years & \\
$18-28$ & $122(52.4)$ \\
$29-38$ & $77(33.0)$ \\
$39-48$ & $26(11.2)$ \\
$49-58$ & $8(3.4)$ \\
\hline Total & 233 \\
\hline
\end{tabular}


Of the 233 donors recruited $176(76 \%)$ donors had titres of $\geq 1: 64$ regardless of antibody specificity or class. The proportion with minimum titre $\geq$
1:64 for $\operatorname{IgM}$ anti-A was $36 \%$, IgM anti-B $26.6 \%$, IgG anti-A $48.1 \%$ and IgG anti-B $32.2 \%$ as demonstrated in Table 2.

Table 2: Distribution of titres of the different antibodies and their frequency

\begin{tabular}{|l|c|c|c|c|c|c|c|c|c|c|}
\hline & \multicolumn{10}{|c|}{ Antibody titrations and proportions (\%) } \\
\hline Antibody class & $\mathbf{0}$ & $\mathbf{1}$ & $\mathbf{2}$ & $\mathbf{4}$ & $\mathbf{8}$ & $\mathbf{1 6}$ & $\mathbf{3 2}$ & $\mathbf{6 4}$ & $>\mathbf{1 2 8}$ \\
\hline IgM anti-A & 0 & $2(0.9)$ & 0 & $7(3.0)$ & $33(14.2)$ & $4318.5)$ & $64(27.5)$ & $52(22.3)$ & $32(13.7)$ \\
\hline IgM anti-B & 0 & 0 & 0 & $15(6.4)$ & $44(18.9)$ & $61(26.2)$ & $51(21.9)$ & $50(21.5)$ & $12(5.2)$ \\
\hline IgG anti-A & $5(2.1)$ & 0 & $2(0.9)$ & $9(3.9)$ & $27(11.6)$ & $23(9.9)$ & $55(23.6)$ & $62(26.6)$ & $50(21.5)$ \\
\hline IgG anti-B & $2(0.9)$ & $1(0.4)$ & $6(2.6)$ & $13(5.6)$ & $35(15.0)$ & $44(18.9)$ & $57(24.5)$ & $39(16.7)$ & $36(15.5)$ \\
\hline \multicolumn{19}{|c|}{} & $76 \%^{\mathbf{a}}$ & $39 \%$ \\
\hline
\end{tabular}

a- The proportion with titre $\geq 1: 64$, b- The proportion with titre $\geq 1: 128$

Age was stratified into groups and using Fisher's exact test, association of high titre among the age groups was assessed. High titre was not associated with any age group $(\mathrm{P}=0.55)$, as shown in Table 3 .

Table 3 Proportion of high titre among age groups

\begin{tabular}{|l|c|}
\hline Age groups in years & $\begin{array}{c}\text { Frequency of High titre } \\
\geq 1: 64(\%)\end{array}$ \\
\hline $18-28$ & $92(52.3)$ \\
$29-38$ & $57(32.4)$ \\
$39-48$ & $22(12.5)$ \\
$49-58$ & $5(2.8)$ \\
\hline TOTAL & $176(100)$ \\
\hline
\end{tabular}

On applying chi-square no significant association was observed in between the proportion of those with high antibody titre and those with low antibody titre among the different age groups $(\mathrm{P}=0.553)$, as demonstrated in Figure 2.

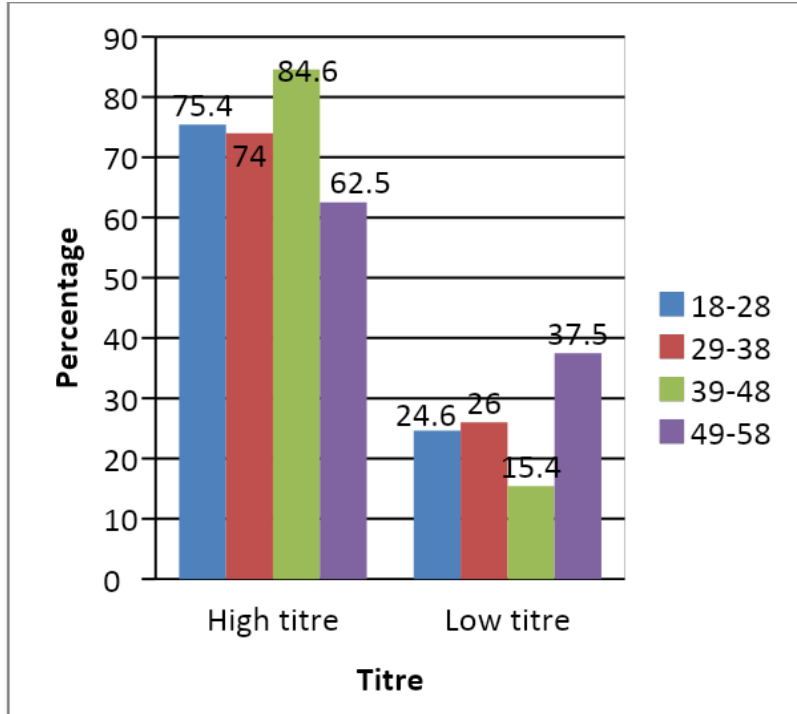

Figure 2: Association between age and antibody titre
There was no significant association in between the proportion of those with high antibody titre and those with low antibody titre with regard to gender ( $\mathrm{P}=0.116)$, as demonstrated in figure 3 .

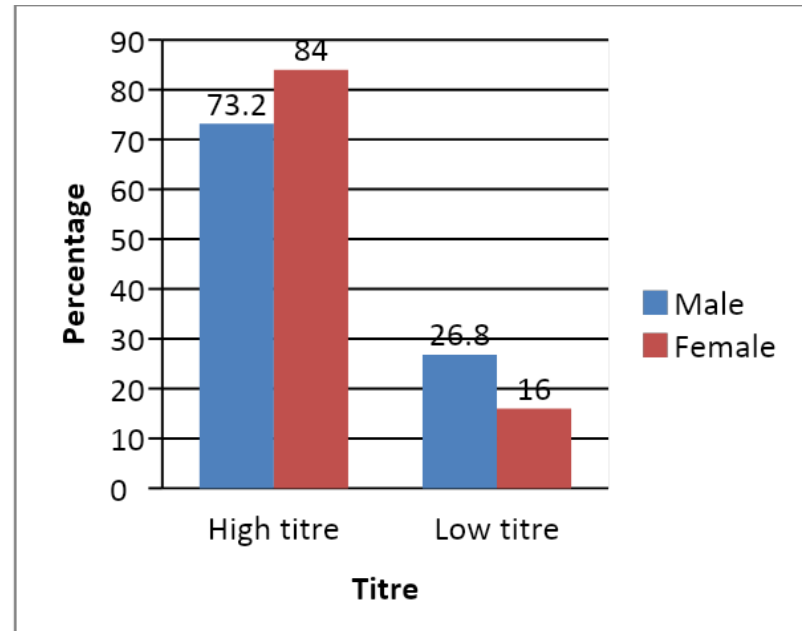

Figure 3: Association between sex and antibody titre

Finally, there was no association found between high titre with history of pregnancy and transfusion ( $\mathrm{P}>0.05)$. However and contrary to expectation high antibody titre was detected among those who did not consume yoghurt ( $p$ value 0.03 ).

\section{Discussion}

Blood is a scarce commodity globally ${ }^{(13)}$. In resource limited countries like Kenya, it is even more rare with annually less than the recommended one percent donation of the country's population ever attained. Of the different blood collected, blood group $\mathrm{O}$ is the most frequent blood type in Kenya constituting nearly $50 \%$ of all blood types ${ }^{(3)}$. 
Relative difficulty in obtaining $\mathrm{ABO}$ specific blood may sometimes lead to transfusion of group $\mathrm{O}$ blood and components in non group $\mathrm{O}$ recipients, especially during emergencies and in cases of neonates requiring transfusion born by $\mathrm{ABO}$ incompatible mothers. The major cross-match test which is usually carried out by reacting patient plasma or serum and donor cells does not take into account donor plasma which may contain high levels of anti-A and/or anti-B antibodies which can lead to transfusion reactions.

In Kenya routine $\mathrm{ABO}$ antibody titration is not mandatory and is therefore not carried out despite the inherent risk. Varying prevalence of $\mathrm{ABO}$ antibodies titre and levels has been reported among African countries. For instance in Nigeria a prevalence of hemolysin ranging from $20-80 \%$ have been shown ${ }^{(14)}$, while in Zimbabwe $60 \%$ of lytic sera were reported to have titre $\geq 1: 64$ of $\operatorname{IgG}^{(15)}$ and in Côte d'Ivoire overall prevalence of hemolysin was found to be $35.08 \%$ at their National Blood Transfusion Centre(10).No published data is available among East African countries on the prevalence of these antibodies.

The overall prevalence of these antibodies in this study was $75.5 \%$. irrespective of antibody class and specificity. A study by Khampanon et al in Thailand reported high frequency of anti-A IgM antibodies of $75.7 \%$ and $80.0 \%$ due to anti-B IgM antibodies, while the frequencies due to anti-A IgG and anti-B $\mathrm{IgG}$ antibodies were $93.0 \%$ and $95.3 \%$, respectively using a cut of $\geq 1: 64^{(16)}$. Environmental factors, enteric bacteria, intestinal parasites and mosquitoes have been suggested to contribute to this high frequency of antibody titre. Comparatively, Kenya being a tropical country, all these factors are prevalent.

In contrast, a recent study in 2015 by Oyedeji et al in Nigeria reported lower prevalence of hemolysin of $18.6 \%$ while Olawumi et al in 2001 demonstrated $18.5 \%$ having titre of $1: 8^{(17)(14)}$. The difference between their results and those in this study could be explained by method of testing. They assessed hemolysin using visual and spectrophotometric end point determination of titre, while the testing in this study involved highly sensitive and fully automated technology looking at both IgM and IgG titre. Low antibody titre was also reported among Brazilian donors $^{(11)}$. The brazilian study used a cut of 1:128 for high titre and saline tube method technique.

Our study did not show significant association between high titre and sex. Similarly, a study conducted by Khampanon at el at the Thailand National Blood Centre found no association between IgM, IgG titre and sex $(\mathrm{P}>0.05)(16)$. A similar study by Mavichak conducted in same setting demonstrated some tendency of higher anti$\mathrm{A}$ and anti-B titres in female than male though not statistically significant ${ }^{(18)}$. Contrarily significant association of high titre among gender have been reported in other studies ${ }^{(9)(11)}$. These studies have associated high antibody titre with the female gender.

Our study also did not find any significant association between high titre and age. However, there are publications that have described a relationship between titre and age ${ }^{(18),(9)}$ mostly pointing out higher prevalence among young age group.

Incompatible transfusion and pregnancy are known to influence antibody titre. Frequency of maternalfetal ABO incompatibility is high among African population $^{(19)}$ which are known to contribute to incidence of ABO Hemolytic Disease of the New born. Universal group $\mathrm{O}$ donor blood transfusion practice is common in Kenya. This study interrogated whether generally a history of past transfusion and pregnancy were associated with high antibody titre. The study did not find significance to these factors. This could be possibly be explained by the few number of those transfused with only five participants ( $2 \%$ of donors) reporting ever transfused. It is also important to note that the study could not determine the ABO nature of pregnancy and blood type among those transfused.

The use of probiotic for long time have been associated with stimulating high antibody production $^{(12)}$, this study also assessed the role of dietary item (yoghurt) in relation to high antibody titre and contrary to expectations, high antibody titre 
was observed among donors who did not consume yoghurt $(\mathrm{P}=0.03)$. The proportion of participant that took yoghurt were $86.7 \%$. The men who did not consume yoghurt had high antibody titre when compared with the female counterpart. Difference in life style among the gender may explain this outcome.

\section{Conclusion}

Due to prevalence of high antibody titre among our group $\mathrm{O}$ donors, the study underscores the importance of pre-transfusion $\mathrm{ABO}$ antibody titration. It is recommended that the use of group $\mathrm{O}$ donor blood and component should be limited to group $\mathrm{O}$ recipients and only be used in other groups when low antibody titre can be established. Since a wide variation of antibody titre has been demonstrated in different geographical locations within the same countries elsewhere, a more robust multi-site study is suggested to determine a national prevalence.

\section{Acknowledgments}

This Research was funded by Kenyatta National Hospital Research and programs department. We thank Mr. Aphonce Kioko for assistance in the testing and laboratory work.

\section{References}

1. Hans Peter Schwarz Friedrich Dorner. Karl landsteiner and his major contributions to haematology. $\mathrm{Br} \quad \mathrm{J}$ Haematol. 2003;121(1):556-65.

2. Helmut Schenkel-Brunner. Human Blood Groups: Chemical and Biochemical Basis of Antigen. 1st ed. Springer-Verlag Wien; 1995. $439 \mathrm{p}$.

3. Mwangi J. Blood group distribution in an urban population of patient targeted blood donors. East Afr Med J. 1999;76(11):615-8.

4. Oluwadare I, Shonekan S. ABO and Rhesus "D" blood type distribution in students admitted into Moshood Abiola Polytechnic, Abeokuta, Nigeria in 2006. African J Biotechnol. 2008;7(11):1641-3.
5. Dass P, Nair S, Harris V, Rose D, Mammen $\mathrm{J}$, Bose $\mathrm{Y}$, et al. Distribution of $\mathrm{ABO}$ and $\mathrm{Rh}$-D blood groups among blood donors in a tertiary care centre in South India. Trop Doct. 2001;31(1):47-8.

6. Sadani DT, Urbaniak SJ, Bruce M, Tighe JE. Repeat ABO-incompatible platelet transfusions leading to haemolytic transfusion reaction. Transfus Med. 2006;16 (5):375-9.

7. Barjas-Castro ML, Locatelli MF, Carvalho MA, Gilli SO, Castro V. Severe immune haemolysis in a group A recipient of a group $\mathrm{O}$ red blood cell unit. Transfus Med. 2003;13(4):239-41.

8. Shah B V, Rajput P, Virani ZA, Warghade S. Baseline Anti-blood Group Antibody Titers and their Response to Desensitization and Kidney Transplantation. Indian J Nephrol. 2017;27(3):195-8.

9. Godin MM, Souza L de O, Schmidt LC, Vieira LM, Diniz RS, Dusse LMSA. Dangerous universal donors: the reality of the Hemocentro in Belo Horizonte, Minas Gerais. Rev Bras Hematol Hemoter. 2016;38(3):193-8.

10. Amah Patricia Victorine G-K, Liliane SK, Honoré AA, Richard YO, Blassonny GDA, Mamadou SY, et al. Prevalence of Anti-A and Anti-B Haemolysins in Group O Blood Donors at the National Blood Transfusion Center of Abidjan, Côte d\&amp;apos;Ivoire. Int J Immunol. 2016;4(6):68.

11. França NDG de, Poli MCC, Ramos PG de A, Borsoi CS da R, Colella R. Titers of $\mathrm{ABO}$ antibodies in group $\mathrm{O}$ blood donors. Rev Bras Hematol Hemoter. 2011;33(4):259-62.

12. Daniel-Johnson J, Leitman S, Klein H, Alter $\mathrm{H}$, Lee-Stroka A, Scheinberg $\mathrm{P}$, et al. Probiotic-associated high-titer anti-b in a group a platelet donor as a cause of severe hemolytic transfusion reactions. Transfusion. 2009;49(9):1845-9.

13. World Health Organization. The 2016 global 
Status Report on blood safety and availability.

14. Oyedeji OA, Adeyemo TA, Ogbenna AA, Akanmu AS. Prevalence of anti-A and anti$\mathrm{B}$ hemolysis among blood group $\mathrm{O}$ donors in Lagos. Niger J Clin Pract. 2015;18(3):32832.

15. Adewuyi J.O. (a) · Gwanzura C. (a) · Mvere D. (b). Characteristics of Anti-A and Anti-B in Black Zimbabweans. Vox Sang. 1994;67(3).

16. Khampanon K, Chanprakop T, Sriwanitchrak P, Setthakarn M, Oota S, Nathalang O. The Characteristics of ABO Antibodies in Group O Thai Blood Donors. J Clin Lab Anal. 2012;26(4):223-6.

17. Olawumi HO, Olatunji PO. Prevalence and titre of alpha and beta haemolysins in blood group "O" donors in Ilorin. Vol. 30, African journal of medicine and medical sciences. 2001. p. 319-21.

18. Mavichak W, Chiewsilp P, Tubrod J, Ovataga P. ABO Antibodies Among Group O Thai Blood Donors.

19. Akomolafe BSO and OF. The frequency of ABO blood group maternal-fetal incompatibility, maternal iso-agglutinins, and immune agglutinins quantitation in Osogbo, Osun State, South-West of Nigeria. Asian J Transfus Sci. 2011;5(1):46-8. 